\title{
CORREO ELECTRONICO DE LA UNIVERSIDAD NACIONAL JORGE BASADRE GROHMANN Y LA RED CIENTIFICA PERUANA
}

Carlos Polo Bravo ${ }^{1}$

Nunca ha sido tan real el dicho: "La información es poder", sobre todo en la actualidad, cuando constatamos diariamente, como las materias primas más caras y más difíciles de hallar en el nuevo orden internacional son sin duda: la INTELIGENCIA y la INFORMACION.

Latendencia de nuestro tiempo es la de construir, a escala mundial, una red troncal donde teléfonos y cables confluyan para acercar servicios como: videoteléfonos, softwares educacionales y televisión por cablea todos los habitantes del planeta. Para ello, la infraestructura básica como las fibras ópticas y los cables coaxiales ya se hallan disponibles, por lo que ahora, se trata de crear las super autopistas del conocimiento y la información que sean capaces de transportar textos, voces, datos e imágenes simultáneamente. No sólo podrátransferirse datos de una computadora a otra por el hilo telefónico, sino que será más fácil armar sistemas globales en tiempo real, que permitan -entre otras cosas- transmitir operaciones entre hospitales a nivel mundial, sacar boletos de avión o tren, imprimir periódicos o revistas a distancia, o hacer un programa personalizado de televisión con acceso a cualquier canal en el mundo.

Todas las redes Internet usan tecnología mixta, provista por las compañías de telefonía local. En nuestro país, las redes digitales de CPT (Midas) y de ENTEL (Red) permiten conectarse a la Red Científica Peruana a una mayor velocidad de transmisión, con más calidad en las imágenes ymayor seguridad en la información durante las veinticuatro horas del día.

Nuestra universidad es usuaria de la RCP para uso del correo electrónico (Electronic Mail: E-Mail), cuyo nodo principal funciona en el Consejo de Investigación (COIN).

1 Licenciado en Física

\section{¿QUE ES EL CORREO ELECTRONICO?}

El correo electrónico (E-Mail) es el corazón de la telemática, implica el envío de mensajes de un computador aotro, desdeun simplememorándumtipeado directamente sobreun sistema "E-Mail» hastaun documento elaborado anteriormente, con un procesador de palabras y llevado de un microcomputador a un sistema E-Mail para su transmisión correspondiente.

El Correo Electrónico está presentado en formato digital o computarizado, algunas veces es confundido con los sistemas telefax. El fax de comunicación, donde una hoja de papel es transmitida por una máquina telefax a través del hilotelefónico, no es tan versátil como el «EMail", aunque la tecnología puede ser similar. El mensaje del Correo Electrónico puede ser enviado a una máquina fax o terminal de télex para oficinas que no tienen Correo Electrónico; en cambio, una máquina fax sólo puede transmitir a otra máquina fax.

Los microcomputadores pueden también adaptarse con terminales de fax que permiten al computador enviar fax digital y recibir de otro fax terminal, pero tienen el inconveniente de requerir, adicionalmente de costosos equipos.

\section{VENTAJAS DEL CORREO ELECTRONICO}

comunicación internacional.

-Es extremadamente rápido, en particular para la -Es ampliamente independiente de las horas de zona mundial.

-Se envía mensajes cuando es conveniente para el usuario y los receptores leen y responden el mensaje cuando es conveniente para ellos.

-Uno se sus mejores beneficios que aporta es que los documentos recibidos vía E-Mail son usados con un propio procesador de palabras, los mensajes llegan en forma digital y al mismo instante se crea los files con procesadores de palabras y sealmacena en el computador donde queda a disposición del usuario para su posterior 
reedición o impresión.

\section{EL CORREO ELECTRONICO PROPORCIONA UN CONSIDERABLE AHORRO DE COSTOS}

-Ahorro de energía eléctrica, yaque en el proceso de envio y de recepción consume pocas unidades de kilovatios-hora.

-Ahorroen el costo de papel, sobresy estampillas.

-Respecto a un mensaje vía fax, elimina el tiempo correspondiente a la impresión (fotocopiado del documento) y hay ganancia en el uso del file electrónico.

-Ahorro en la llamada telefónica. El acceso al EMail es como una llamada local, si lo comparamos al costo de una llamada a larga distancia o internacional requerida para el acceso al fax.

- $-E l$ "E-Mail» es también más preciso y eficiente que las conversaciones telefónicas, ya que más detalles sepueden enviar en un escrito. Además se evita la espera requerida para la localización de la persona.

\section{EQUIPO NECESARIO PARA EL CORREO ELECTRONICO}

La conección al Correo Electrónico es frecuentemente simple, si se tiene un microcomputadory un teléfono en oficina. Sólo dos cosas adicionales faltan: un "modem" para conectar la computadora al teléfono y un "Software" de comunicación para enviar y recibir mensajes. El "Modem" y el "Software" de comunicación son fáciles de adquirir y a precios cómodos.

El "modem" acopla su computador al sistema telefónico, es acrónico para «Modulate/DEModulate». El "modem" modula (cambia) la señal digital de su computador en precisas señales de sonido que son transmitidas por la línea telefónica, En el terminal receptor, otro «modem» demodula aquellos sonidos, convirtiéndolos en señal digital para el computador receptor.

Los «modems" se caracterizan por su velocidad detransmisión dela información. Existen desde 1200 bps ("bits" por segundo), 2400 bps, hasta 9600 bps. Cuanto mas sean los bps, mejor será la velocidad de transmisión de la información; es decir, menos tiempo de uso del teléfono, por consiguiente, un ahorro en los costos. EI "modem" más usado es el de 2400 bps, tiene gran seguridad en la transmisión, debido a su tecnología avanzaday funciona con el standar internacional telefónico de la U.S.Bell y CCITT. Su costo en el mercado es alrededor de los 150 dólares USA.

Existen varios "software" de comunicación permitidos para usar en el computador conectado al Correo Electrónico. El programa de Comunicación más común es el "kermit», "software» desarrollado por la Universidad de Columbia, y que puede obtenerse fácilmente. También hay "softwares" de comunicación comerciales, tales como: "Procomm" y "SmartCom.". Los precios de los "software" de comunicación van incluidos en el «modem».

\section{CONECCION A UN SISTEMA DE CORREO ELECTRONICO}

Laespinadorsal del sistema de Correo Electrónico Internacional es "INTERNET», una combinación de miles de diferentes sistemas E-Mail individuales que usan la misma técnica estándar y que pueden intercambiar mensajes entre sí.

Una dirección electrónica tiene un sólo nombre sobre uno de los sistemas conectados a Internet, tales como Bitnet/EARN, NetNorth; Gulfnet, Arpanet, oUUCP. Algunas direcciones electrónicas tienen nombre alternativo; por ejemplo, la dirección electrónica:

coin@unjbg.edu.pe en el que:

COIN, es el usuario (interno de la Universidad). @, significa “a”.

Unjbg, el usuarios es la Universidad Nacional Jorge Basadre Grohomann.

Edu, es la institución educativa, y

pe, que se ubica en el Perú.

También existe el servicio de Correo Electrónico Comercial, disponibleatravés decorporaciones privadas, postales nacionales y de autoridades de telecomunicaciones.

\section{LA RED CIENTIFICA PERUANA (R.C.P):}

La R.C.P es una red telemática nacional que permite a sus usuarios acceder a la información regional, nacional einternacional, interconectando sus ordenadores con las principales redes académicas y comerciales de nuestro planeta, tales como: UUNET, Binet, Internet, Geonet, Peacenet, Mci Mail, Compuserve, Dialog, Fidonet, etc.

La R.P.C. esta conformada por numerosas instituciones: universidades, organizaciones no gubernamentales, organismos estatales, y organismos privados.

Los servicios que ofrece la RCP son: 

a) Mensajería electrónica nacional e internacional (E-Mail).
b) Transporte de datos (FTP).
c)Servicio de valor agregado:

- Faxs (ASCII) y télex internacional.

- Noticias nacionales e internacionales.

- Banco datos nacionales e internacionales.

- Grupos de interés nacionales y Extranjeros.

- Servidor de listas con direcciones nacionales e internacionales.

d) Instalación técnica y conectividad.

e) Servicio de desarrollo técnico.

f) Servicio de atención al usuario final.

La RCP funciona las 24 horas del dia y tiene habilitadas líneas telefónicas dedicadas y circuitos especiales por 25 (Perunet) que permiten conectarse a la red en cualquier momento y desde cualquier lugar del país que tenga acceso telefónico. Actualmente están trabajando para el acceso a RCP vía satélite y vía radio. lo que permitirá la conección con todo el Perú.
El "software" de comunicación que usa la RCP es el PcCorreo, que permite la preparación de la correspondencia operando en forma local (lo que minimiza los costos de transmisión) y en forma diferida, es decir, los mensajes son almacenados hasta que se considere conveniente establecer una comunicación con el nodo distribuidor. Durante este proceso ocurre el intercambio de mensajes en ambos sentidos: el envío de aquellos generados localmente y la recepción de los pendientes en el sistema remoto.

La RCP pone a disposición más de 50 LISTAS DE INTERES, las cuales son una herramienta Internet muy difundida, que permiten intercambiar información sobre un tema específico con cientos de personas que tienen el mismo interés. Una vezinscrito en una lista, se puede enviar una opinión o información (sobre el tema de la discusión) a la lista, llegando el mensaje de manera automática a todos los inscritos. De esta forma, las Listas de Interés se convierten en una conferencia electrónica dondetodoslos días los participantespueden intercambiar mensajes. Estas Listas son:

HELP
INDEX
ajedrez
arquitectura
avifauna
bases
cent-jcm
colmena
computo
cosmos
derhuman
economía
educación
electrónica
energía
enigmas
eventos
fddi
física
futbol
hipertex
industrial
info-nets
infocedo
intf
ioper
isis
isisi
k12
laspau
latam-econ
mac

Ayuda para el correcto uso de las listas. Indice de las lista RCP. Lista de Ajedrez. Lista de Arquitectura. Lista de Protección de Aves Lista de Productos de información y BD. Centenario del nacimiento de José C. Mariátegui Lista de Ciencia Ficción suscrita alista Alfa-1 Lista Colmena de Cultura.

Lista de Astronomía en Castellano.

Lista de Derechos Humanos.

Lista de Economia.

Lista de Educación.

Lista de Electrónica.

Lista de Energia.

Lista de Enigmas y Fenómenos Inexplicables.

Lista de Cursos, Congresos, Exposiciones, etc.

Lista de Fibra óptica y FDDI.

Lista de Física.

Lista de Fútbol.

Lista para los interesados en hipertextos.

Lista del Industrial.

Lista Internacional de Administradores de Red.

Lista de Noticias para peruanos en el exterior.

Lista Internacional para Soporte Técnico voluntario.

Lista de Interesados en Investigaciones operativas.

Lista de usuarios para el programa Isis.

Lista inscrita a la lista Internacional Isis.

Lista Primaria y Secundaria.

Lista de Educacirganismo Internacional.

Lista de Economía Latinoamericana.

Lista de Usuarios de Masontoch. 


$\begin{array}{lcl}\begin{array}{l}\text { medambien } \\ \text { mesa-1 }\end{array} & : & \begin{array}{l}\text { Lista de Medio Ambiente. } \\ \text { mic-elec }\end{array} \\ \text { mineria } & : & \text { Lista acerca de redes AL\&C. } \\ \text { noticias } & : & \text { Lista de Minería. } \\ \text { notired } & : & \text { Lista de Acontecimientos. } \\ \text { notisur } & : & \text { Lista de Noticias RCP, sobre redes. } \\ \text { novell } & : & \text { Lista de Interesados en Novell. } \\ \text { novelli } & : & \text { Lista inscrita a la Lista Internacional Novell } \\ \text { objetos } & : & \text { Lista de Orientación al Objeto. } \\ \text { peru } & : & \text { Lista para Peruanos en el Extranjero. } \\ \text { pmail } & : & \text { Lista de Pegassus Mail. } \\ \text { programa. } & : & \text { Lista de Programación (Pascal, C, etc). } \\ \text { radioprot } & : & \text { Lista de Radio Protección (Ipen). } \\ \text { redalc } & : & \text { Lista del Proyecto REDALC (CEE). } \\ \text { salud } & : & \text { Lista de Salud. } \\ \text { tarifas } & : & \text { Lista de Tarifas y Legislación de Redes. } \\ \text { treminometro } & : & \text { Lista de Terminología y Lingüística. } \\ \text { todos } & : & \text { Lista de Postmaster de la RCP. } \\ \text { unix } & : & \text { Lista de información sobre Unix. } \\ \text { waffle } & : & \text { Lista de Información sobre Waffle. } \\ \text { windows } & : & \text { Lista de Usuarios/Programadores Windows. } \\ \text { wawa } & : & \text { Lista de Temas relativos a la infancia. }\end{array}$

Las direcciones electrónicas de las dependencias académicas, administrativas, Centros de investigación, de Extensión y Proyección de nuestra universidad son:

coin@unjbg.edu.pe redo@unjbg.edu.pe viac@unjbg.edu.pe viad@unjbg.edu.pe faci@unjbg.edu.pe fame@unjbg.edu.pe faim@unjbg.edu.pe faip@unjbg.edu.pe faca@unjbg.edu.pe facf@unjbg.edu.pe fcag@unjbg.edu.pe faia@unjbg.edu.pe face@unjbg.edu.pe faen@unjbg.edu.pe faob@unjbg.edu.pe coep@unjbg.edu.pe cert@unjbg.edu.pe rchavez@unjbg.edu.pe isged@unjbg.edu.pe cetroped@unjbg.edu.pe ceid@unjbg.edu.pe ceima@unjbg.edu.pe ifotec@unjbg.edu.pe
Consejo de Investigación.

Rectorado.

Vice-rectorado Académico.

Vice-rectorado Administrativo.

Facultad de Ciencias.

Facultad de Ingeniería Metalúrgica.

Facultad de Ingeniería de Minas.

Facultad de Ingeniería Pesquera.

Facultad de Ciencias Administrativas.

Fac. de Cs. Contables y Financieras.

Facultad de Ciencias Agrícolas.

Facultad de Ing. Industrias Alimentarias.

Facultad de Ciencias de la Educación.

Facultad de Enfermería.

Facultad de Obstetricia.

Centro de Extensión y Proy. Universitaria

Centro de Energías renovables de Tacna.

Proyecto Centro Internacional de la Papa.

Instituto de Investigación Sisma y Geotecnia.

Centro de Producción de tecnología pesquera.

Centro de Idiomas.

Centro de Investigación del Medio Ambiente.

Oficina de Cooperación Técnica 


\section{PREMIO CONCYTEC A LA CREATIVIDAD CIENTIFICA}

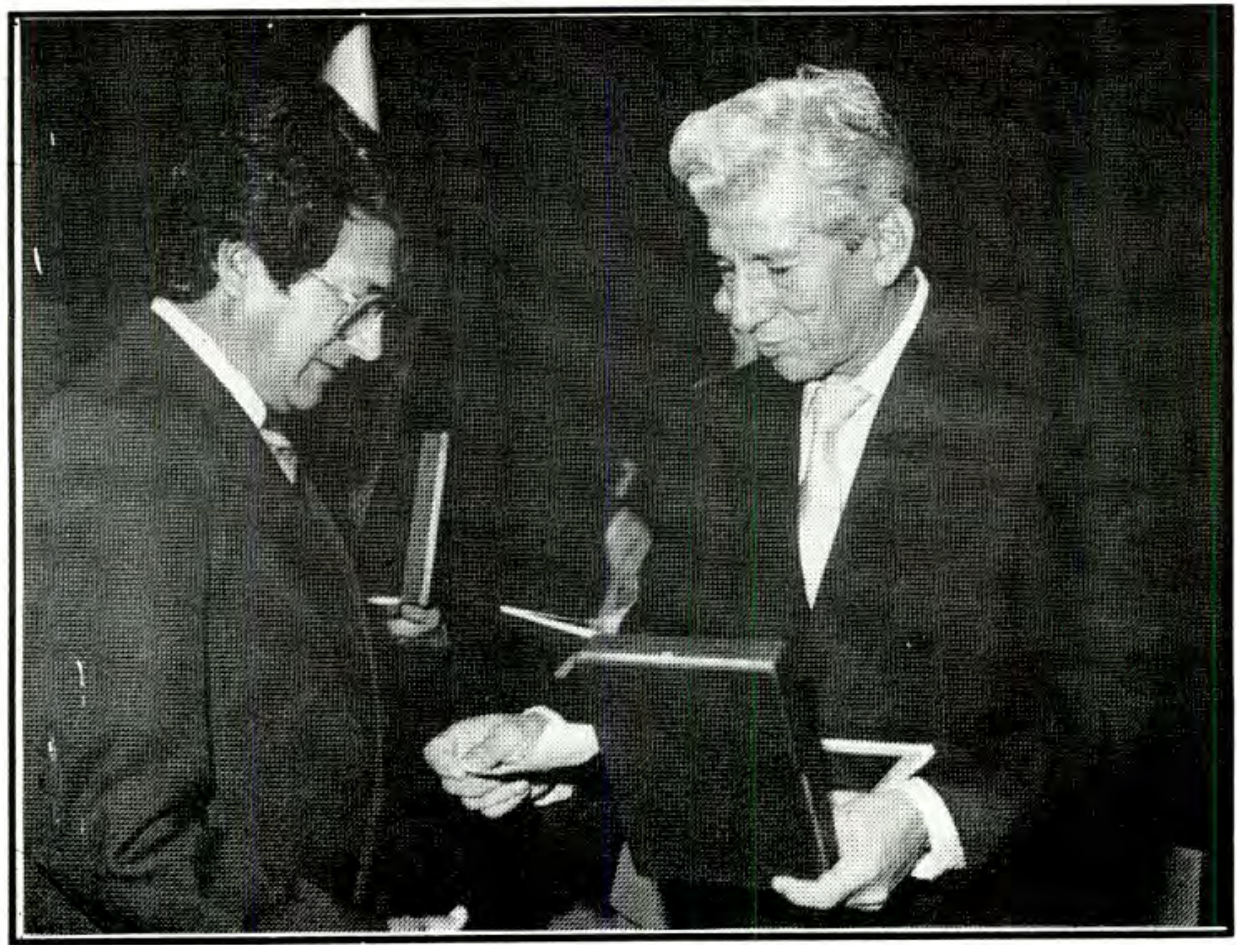

(Foto 1) El Presidente del CONCYTEC hace entrega del Premio al Dr. René Chávez, en ceremonia del 12 de enero de 1995, en el Colegio de Ingenieros del Perú, Lima.

El descubrimiento de la variabilidad genética resistente a la salinidad y sequía en el germoplasma inicial de papa y camote,que tuvo lugar a comienzos de 1985, estimuló la investigación aplicada sobre las respuestas genotípicas de las plantas tuberíferas a los estreses abióticos en las zonas áridas de potencial agrícola. Cerca de diez años de investigación colaborativa han transcurrido desde entonces, bajo el liderazgo científico de René Chávez Alfaro y Humberto Mendoza, quienes desarrollaron,junto con su equipo de esforzados investigadores, continuos programas de cruzamiento y selección para generar clones superiores, y progenitores de buena habilidad combinatoria adaptados a las condiciones de la naturaleza peruana.

El germoplasma mejorado,una vez liberado, está siendo utilizado por los agricultores de la zona agroecológica de Tacna y Moquegua, demostrando espectacular rendimiento en la alimentación humana, así como su aprovechamiento en forraje y materia prima para la agroindustria.

Resultado de esta valiosa experiencia es el trabajo AMPLIANDO LA BASE GENETICA PARA RESISTENCIA A SALINIDAD Y SEQUIA EN EL GERMOPLASMA MEJORADO DE PAPA Y CAMOTE, cuyos autores, siempre bajo el liderazgo de René Chávez y Humberto Mendoza,obtuvieron en los inicios de este año el Premio Nacional a la Creatividad Científica, otorgado por el Consejo Nacional de Ciencia y Tecnología (CONCYTEC), como reconocimiento a su contribución al desarrollo de la agricultura nacional.

La Universidad Nacional Jorge Basadre Grohmann y el Centro Internacional de la Papa (CIP),entidades auspiciadoras de la investigación, se 
sienten partícipes del premio y reafirman una vez más la importancia de fomentar la convergencia institucional en los trabajos científicos.

De manera particular,el Consejo de Investigación (COIN) de la Universidad Jorge Basadre Grohmann expresa su regocijo y una cálida felicitación al equipo científico conformado por:
Dr. René Chávez Alfaro

Dr. Humberto Mendoza (CIP) MSC Jorge Espinoza (CIP) Ing Josué Flores Ing Juan Chávez Bch Porfirio Siles Bch Marco Huacollo

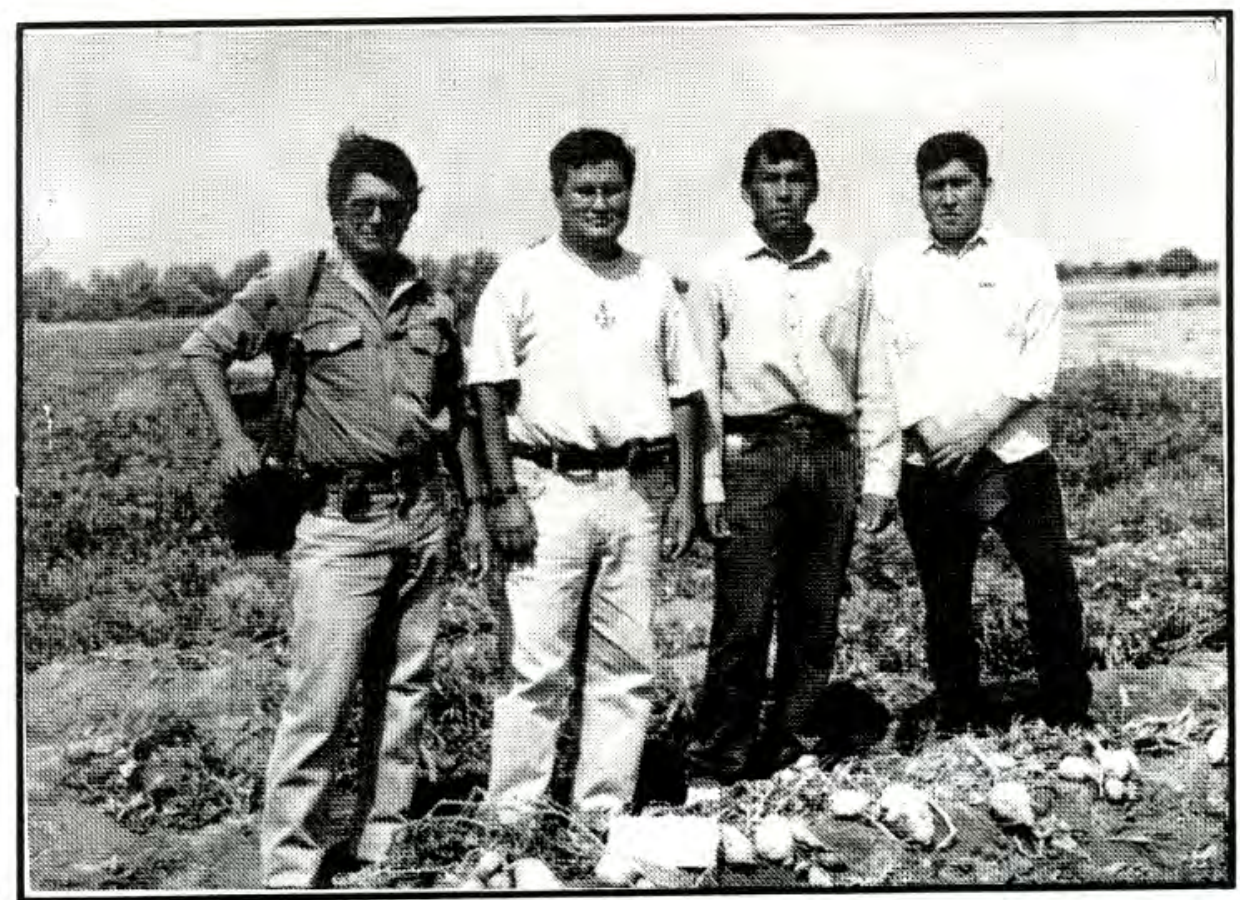

(Foto 2) Equipo de investigadores de la UNjBG. en el Centro i perimental Agricola La Yarada. De izquierda a derecha: René Chávez, Marco Huacollo, Porfirio Sılés y Josué Flores. 


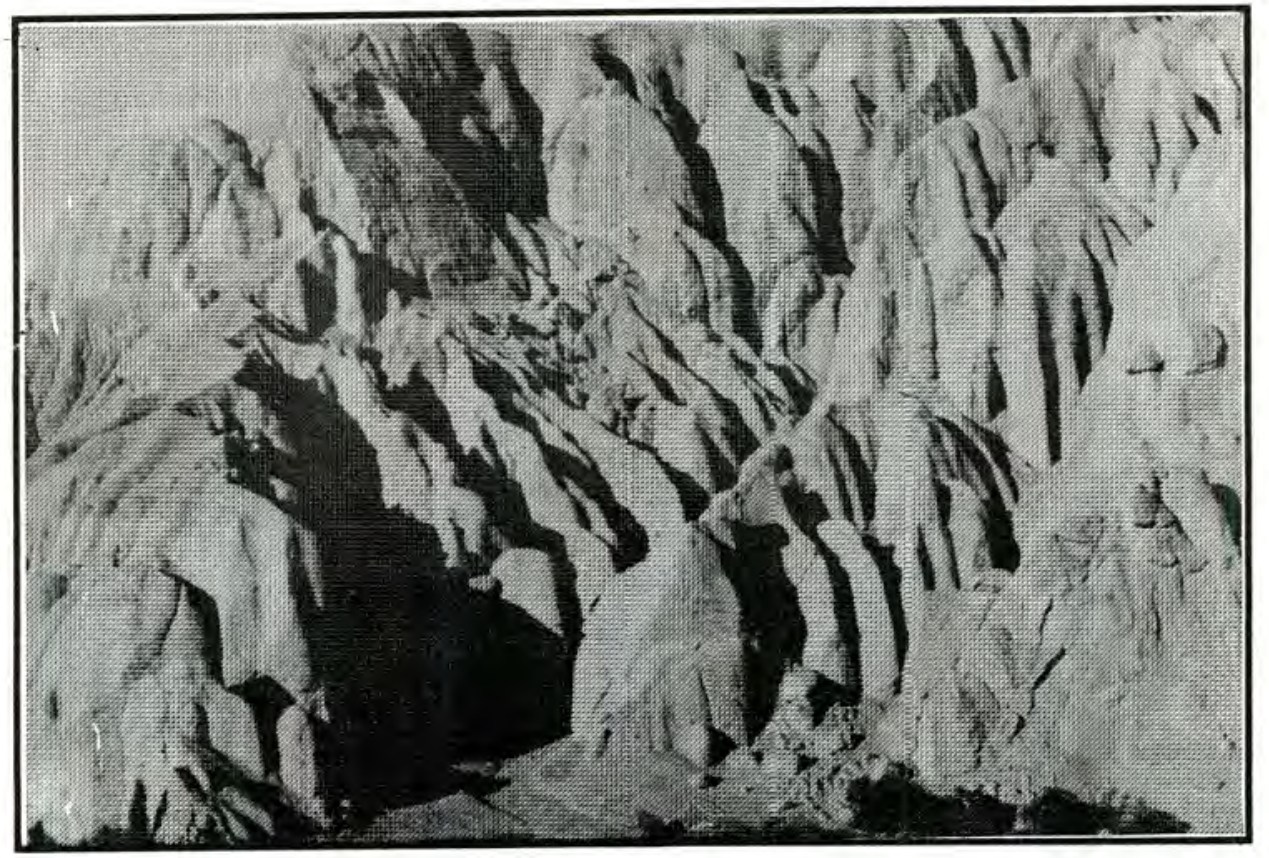

El suelo ha constituido el principal desafío para el hombre andino al que supo responder con estoicismo y creatividad.

Arriba: arcilla de la formación moqueguana fuertemente erosionada, vista de oeste, Ilabaya. Abajo: andenerías de Candarave, de factura prehispánica.

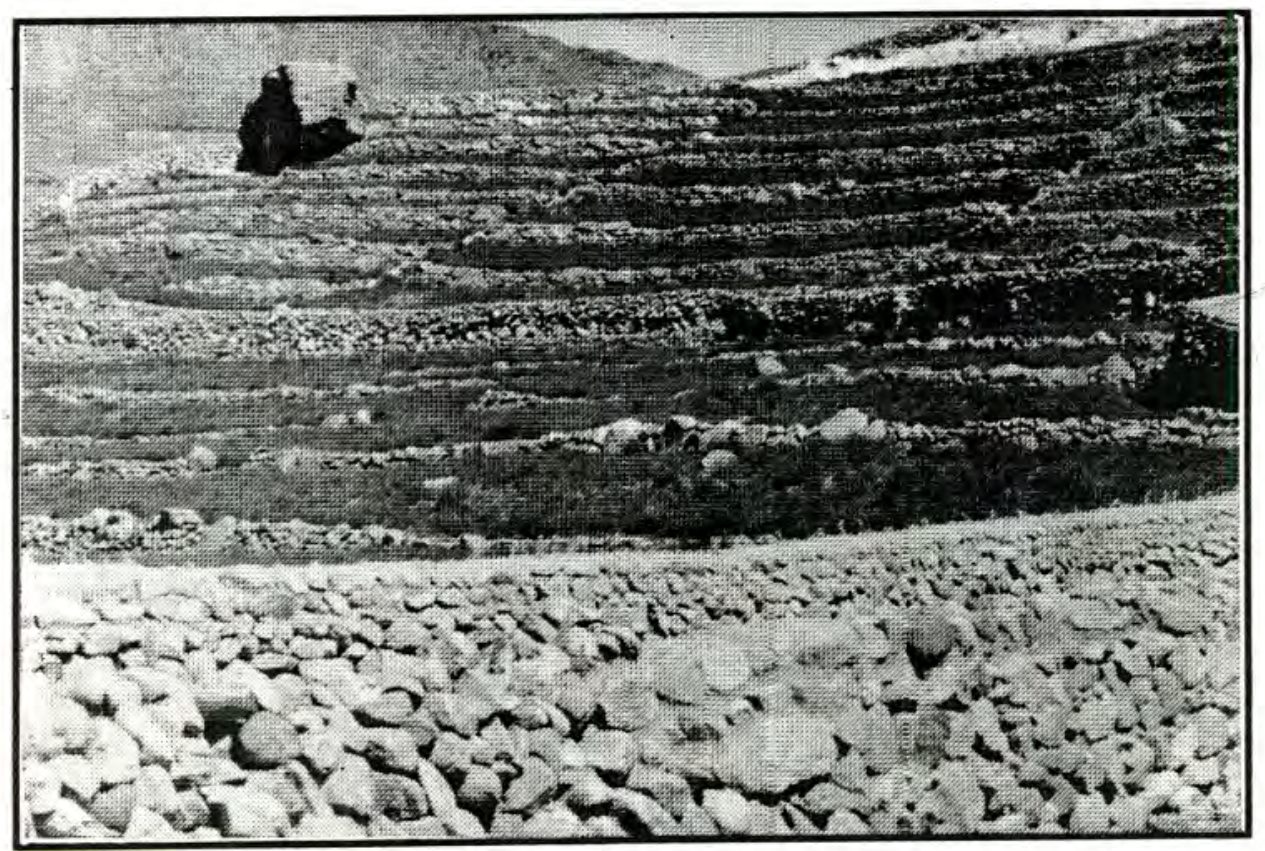

